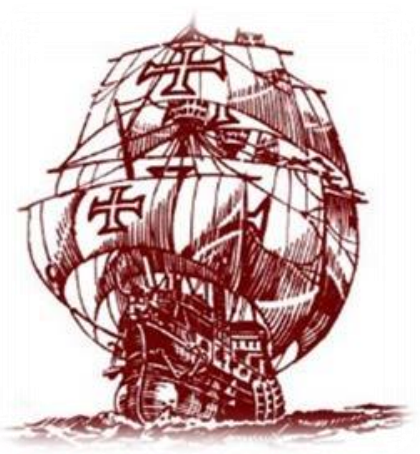

Nau Literária: crítica e teoria de literaturas

www.seer.ufrgs.br/nauliteraria

ISSN 1981-4526 - PPG-LET-UFRGS - Porto Alegre

Vol. 11 N. $01-2015$

100 anos da geração Orpheu

\title{
Tecendo apontamentos filosóficos sobre António Lobo Antunes: uma leitura existencialista da crônica Em caso de acidente
}

\author{
Francisca Marciely Alves Dantas ${ }^{1}$
}

\begin{abstract}
Resumo: O presente artigo objetiva analisar a crônica Em caso de acidente, publicada em 2002, do escritor português contemporâneo António Lobo Antunes, dando ênfase à configuração delineada entre as marcações temporais e a própria existência, a qual se descortina na prosa romanesca antuniana. Desse modo, a leitura crítica aqui apresentada busca ressaltar de que maneira o tempo interfere na condição subjetiva do personagem central da referida crônica, colocando em confronto dois estados da consciência humana separados por um tempo e espaço consideráveis e que suscitam um olhar perscrutador no presente. As obras $O$ ser e o nada (SARTRE, 2008) e Ser e tempo (HEIDEGGER, 2002) fundamentam o estudo aqui proposto, buscando circunscrever os estágios ontológicos: em-si, para-si e para-outrem, explicitando o que podemos caracterizar de subjetivismo do ser.
\end{abstract}

Palavras-chaves: Literatura; Filosofia; Crônica; António Lobo Antunes.

Abstract: This article aims to analyze the chronicle Em caso de acidente, published in 2002, by contemporary portuguese writer António Lobo Antunes. It emphasizes the configuration outlined between the time marks and the own existence which unfolds in novelistic prose by Antunes. Thus, this critical reading presents how the time interferes in the subjective condition of central character in story confronts with two conscientious nuances separated by a considerable time and space, which provide an examiner look in the present time. The works $O$ ser e o nada (SARTRE, 2008) and Ser e tempo (HEIDEGGER, 2002) are underlying in this propose of study, above all, to circumscribe the ontological stages: em-si, para-si and para-outrem, these concepts explain what we can characterize subjectivism of being.

Keywords: Literature; Philosophy; Chronic; António Lobo Antunes.

Debaixo do céu há momento para tudo, e tempo certo para cada coisa: Tempo para nascer e tempo para morrer. Tempo para plantar e tempo para arrancar a planta. Tempo para matar e tempo para curar. Tempo para destruir e tempo para construir. Tempo para chorar e tempo para rir. Tempo para gemer e tempo para bailar. Tempo para atirar pedras e tempo para recolher pedras. Tempo para abraçar e tempo para se separar. Tempo para procurar e tempo para perder. Tempo para guardar e tempo para jogar fora. Tempo para rasgar e tempo para costurar. Tempo para calar e tempo para falar. Tempo para amar e tempo para odiar. Tempo para a guerra e tempo para a paz.

Eclesiastes 3, 1-8. In. A Bíblia.

\footnotetext{
${ }^{1}$ Mestranda em letras - estudos literários (UFPI) e bolsista da Capes na área de literature portuguesa contemporânea
} 
Debruçar-se sobre as páginas espelhos da ficção de António Lobo Antunes nos leva a penetrar profundamente em sua escritura labiríntica ${ }^{2}$. Imbuída de um caráter fragmentário, seja nas marcações temporais ou na organização sintática, a escrita literária engendrada pelo autor possibilita a abordagem de temas que permeiam o ser humano em sua constante luta em torno de si mesmo e de suas agruras existenciais. Suas obras revelam uma sutileza na linguagem e uma narrativa que se constrói de forma não linear, fugindo à tradição romanesca. Massaud Moisés explica que o autor português:

Cultiva desde o início um realismo sem condescendências, direto, franco, quase cruel ou cínico, tendo como pano de fundo ou temática os acontecimentos contemporâneos e, como instrumento de prospecção, análise e hermenêutica, a sua experiência de médico psiquiatra (por sinal patente em mais de uma obra, notadamente nas primeiras), vazado numa linguagem sôfrega, de unívoca e ácida inflexão, que não hesita ante as "obscenidades pontiagudas", impressas por vezes em maiúsculas, como a gravar com ferro em brasa "a longa travessia do inferno", que é o hospital psiquiátrico, "reino das flores de plástico", metonímia e espelho da vida. (MOISÉS, 2008, p. 528-529)

E é exatamente esse universo desconexo, que pode ser visualizado nos fragmentos de vivências dos personagens intercalando passado e presente, que se delineia na ficção de António Lobo Antunes e que nos move e desafia enquanto leitores críticos. Inserido em um contexto em que a esfera literária passa por transformações no que concerne à produção e recepção da ficção portuguesa contemporânea, António Lobo Antunes se destaca por explorar técnicas narrativas inovadoras, em que os planos temporais se sobressaem diante do enredo que é construído, interpondo vozes narrativas e conduzindo a ação dos personagens para um eixo problemático conflituoso, uma vez que figura em cena uma tensão temporal, evocando passado e presente simultaneamente. Como bem aponta Álvaro Cardoso Gomes:

[...] o passadismo resulta na estagnação do presente, numa alienação cada vez mais profunda diante da realidade, visto que o retorno nada mais é que negação dessa mesma realidade, ou ainda, vivência de uma realidade vicária, projetada num espaço imaginário. Isso porque o passado não ressurge em bloco - a consciência em crise elabora uma seleção, que visa a preservar somente aquilo que seja o oposto da crise do presente. Outro aspecto importante a ser considerado: os fatos pretéritos recuperados pela memória beneficiam-se de uma sintaxe mais livre, se considerarmos sua subordinação interna de acontecimentos. $\mathrm{O}$ projetor das imagens do passado pode, à sua vontade, jogar com a cadeia de fatos, de maneira a encontrar relações que o beneficiam. (GOMES, 1993, p. 4)

\footnotetext{
2“A ficção moderna liberta-se da coação absoluta do enredo e lança novas luzes sobre a personagem, a quem as coisas acontecem, rompendo-se o equilíbrio entre o 'mundo dos factos' e o 'mundo dos valores', uma vez que se estabelece um nítido predomínio das personagens sobre o suceder dos eventos, fugindo-se ao culto da história pela história. [...] Estilhaços de pensamentos, fragmentos sem sentido, trechos fraseológicos aparentemente desconexos, constroem novos significados que podem refletir, de modo convincente, a perplexidade de um mundo flutuante, fragmentário e sem contornos definidos, representando a natureza enigmática do homem, cujos valores em mudança refletem-se no próprio texto ficcional”. (FLORY, 1997, p. 14-15, grifo da autora)
} 
Tecendo apontamentos filosóficos sobre António Lobo Antunes: uma leitura existencialista da crônica Em caso de acidente

Nesse sentido, a crônica Em caso de acidente (2002) caracteriza-se por ser uma narrativa fluida, em que passado e presente se fundem perfazendo um mosaico representativo do viver humano. A transitoriedade se firma como aspecto principal, condensando histórias que exteriorizam o subjetivismo ontológico dos personagens. No referido texto, António Lobo Antunes revela um personagem evasivo - um médico aposentado e escritor - que ao reencontrar os dias de sua juventude, por meio de suas lembranças, reflete dolorosamente sobre sua existência, a partir da compreensão das nuances temporais e do exame de sua consciência: um tempo perdido que não volta mais, um simulacro de uma vida que poderia ter sido e não foi. Sob esse prisma, é importante ressaltar a maneira como o passar do tempo é capaz de elaborar respostas às interrogações que permeiam a existência do homem, instigando-o ao amadurecimento psíquico e à tomada de consciência. Entretanto, assumir a consciência de si mesmo é aceitar a condição de ser livre: restam-lhe ao homem somente escolhas.

Ligo à televisão. Não entendo o que se passa no écram mas continuo a ver. Uma criança sorrime do aparelho. Infelizmente o sorriso dura pouco tempo. Se calhar nem sequer um sorriso. Se calhar sou apenas eu que necessito de um sorriso. Há momentos na vida que precisamos tanto de um sorriso. À falta de melhor toco-me com o dedo no caixilho. (ANTUNES, 2002, p. 45)

Esse tempo abolido e guardado na memória faz com que o médico tenha uma vivência íntima com outro "eu", visualizado através de relances de imagens, que se configuram em sua consciência. E essa manifestação do transitório acontece em instantes de tensão e questionamento em torno da existência, os quais são arquitetados pela ruptura inesperada do tempo, engendrando no indivíduo uma nostalgia sublime e reveladora, conduzindo-o a uma reflexão doce-amarga a respeito da própria condição existencial.

A escrita provocativa de António Lobo Antunes recria no espaço ficcional as contradições que condenam o indivíduo, uma vez que o paradoxo da existência se consolida na superfície linguística do texto por meio da interligação dos tempos, pondo em choque passado e presente. A análise da função do tempo no romance moderno assume um papel fundamental, uma vez que a existência está condicionada nos limites da temporalidade, dando margem para o introspectivo dos personagens, esboçando seus traços psicológicos e deixando transparecer os seus conflitos internos. Assim, o fluxo de consciência demarca as experiências vivenciadas pelos personagens.

A explicação é que enquanto estamos vivendo através de períodos de tédio e vazio ou aguardando impacientemente alguém ou algo desejado com ansiedade, o tempo parece arrastar-se pela falta de pontos de interesse para prender a atenção. Poucos eventos - mentais ou físicos - são oferecidos para que a eles a consciência se prenda, e onde não há nenhuma sensação de sequência ou mudança, a passagem do tempo é vagarosa e as horas parecem mais longas. (MENDILOW, 1973, p. 134) 
Desse modo, a passagem contingencial do tempo constitui leitmotiv do estudo aqui proposto, tendo como foco a observação dos personagens e a forma como estes se desdobram poeticamente na instância narrativa. Levando em consideração esse aspecto, o texto literário do autor português provoca uma reflexão sobre o mal-estar do homem pós-moderno e sua complexa desordem íntima instigada pelo caráter efêmero de suas experiências, explicitando fragmentos de vivências que se contrapõem na linha contínua do tempo.

O confronto existencial condensado a partir da dimensão do tempo causa no ser estranhamento e conflito engendrando interrogações que o lançam ao embate de si por si mesmo. Tema discutido desde a Antiguidade, partindo da filosofia socrática, a responsabilidade do homem diante das suas escolhas contempla um estágio autêntico do viver humano, desvendando no mesmo um pleno cuidado de $\mathrm{si}^{3}$. A representação da brevidade da vivência humana é alcançada de forma bastante peculiar e sensível na escrita do autor português, suscitando indagações a respeito do estar-no-mundo.

É interessante, ainda que de maneira breve, enfatizar a relação que há entre o gênero crônica e a corrente existencialista, uma vez que ambos partem do mesmo ponto de significação e se aproximam dialeticamente: o instante vivido ${ }^{4}$, a experiência cotidiana; tornando-se, por vezes, o que poderíamos designar de um presente inacabado. A filosofia existencialista possibilita ao homem o poder incessante da escolha, a qual é tomada a cada instante, em qualquer circunstância de sua existência. Dessa forma, a apropriação da definição de Angélica Soares acerca da crônica torna-se indispensável:

Ligada ao tempo (chrónos), ou melhor, ao seu tempo, a crônica o atravessa por ser um registro poético e muitas vezes irônico, através do que se capta o imaginário coletivo em suas manifestações cotidianas. [...] E enquanto literatura, ela capta poeticamente o instante, perenizando-o. (SOARES, 1993, p. 64)

Sem a pretensão de esgotar a definição do gênero crônica, considerem-na, ainda que de maneira figurada, como um pedacinho de tempo da existência humana, e que juntamente com outros tantos perfazem o que se poderia caracterizar como a trajetória existencial do homem. Contudo, as escolhas realizadas nesses pequenos instantes temporais provocam mudanças e

\footnotetext{
3 “(...) O cuidado de si não tem sentido senão na perspectiva do cuidado dos outros: é preciso cuidar de si, para poder engajar-se na vida política. Sócrates é, nesse sentido, aquele que fez descer a filosofia de sua torre de marfim para operar uma verdadeira conversão na escala dos valores humanos. O 'pôr de lado' o não-essencial em benefício do essencial - saber o que somos - é a expressão sintomática de uma consciência aguda do trágico da existência”. (HUISMAN, 2001, p. 16)

4 “(...) estamos perpetuamente ameaçados pelo instante. Ou seja, somos de tal modo, pela própria escolha de nossa liberdade, que sempre podemos fazer aparecer o instante como ruptura (...)”. (SARTRE, 2008, p. 574, grifo do autor)
} 
Tecendo apontamentos filosóficos sobre António Lobo Antunes: uma leitura existencialista da crônica Em caso de acidente

trazem consigo respostas, imediatas ou não. Estando o ser humano condenado à liberdade ${ }^{5}$, o mesmo é responsável por suas escolhas e as consequências advindas destas. Porém, essa mesma liberdade que o singulariza acaba por envolvê-lo em uma atmosfera de incerteza e desespero em determinados momentos, uma vez que não há uma força exterior que o leve ao domínio exato dos caminhos da resolução humana.

Seguindo o que fora ensinado por SARTRE (2008, p. 678) em seus postulados existencialistas, o indivíduo é confortado com a possibilidade de mudar, sendo-lhe oferecida a chave, por vezes enigmática, para a condição autêntica: a liberdade de escolher. Essa condição de ser livre confere ao ser fugir de qualquer definição exaustiva de si mesmo, pois conforme assinala a filosofia sartriana "A existência precede a essência" 6 .

Como bem ressaltou Martin Heidegger, essa dimensão do humano elucida a "maneira de visualizar o ser, de compreender e apreender conceitualmente o sentido, a preparação da possibilidade de uma escolha" (HEIDEGGER, 2002, p. 45), estado intrínseco ao ser e que se explicita de maneira sufocante. Na crônica Em caso de acidente (2002) desvendamos a postulação do estranhamento, das sensações desconhecidas, e que conduz o personagem ao confronto consigo mesmo: a angústia. Inevitável não relacionar o viver humano, sob uma perspectiva sartriana, ao feliz acidente de existir, uma vez que lançado de maneira absurda no mundo, o homem se vê preso nas amarras da própria existência, sendo condicionado a procurar respostas para as interrogações que o enovelam.

O conflito angustiante vivido pelo personagem, médico e escritor, o leva a pensar desesperadamente no suicídio, na limitação da vida como forma de pôr fim às questões ontológicas que perpassam em sua consciência. A cena dramática da existência do personagem se completa, metaforicamente, como um deslocamento, um lugar a ser encontrado, a ser descoberto. No entanto, o insustentável peso da responsabilidade e da escolha o impede de encontrar a si mesmo, causando um desequilíbrio assustador, tendo em vista que "é na angústia que o homem toma consciência de sua liberdade" (SARTRE, 2008, p. 504), ou seja, todas as possibilidades estão ali, diante dele, resta-lhe a tomada de decisão:

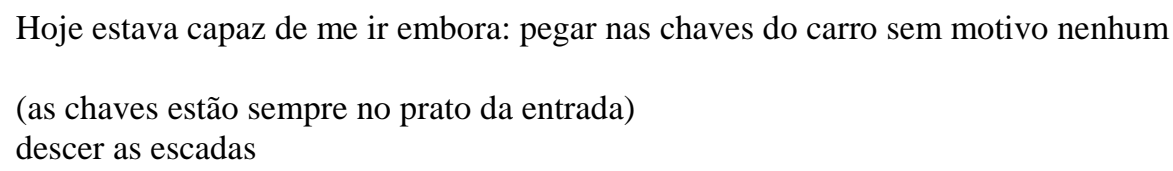

\footnotetext{
5 “O homem, estando condenado a ser livre, carrega nos ombros o peso do mundo inteiro: é responsável pelo mundo e por si mesmo enquanto maneira de ser. Tomamos a palavra 'responsabilidade' em seu sentido corriqueiro de consciência (de) ser o autor incontestável de um acontecimento ou de um objeto”. (SARTRE, 2008, p. 678)

6“A liberdade humana precede a essência do homem e torna-a possível: a essência do ser humano acha-se em suspenso na liberdade”. (SARTRE, 2008, p. 35)
} 
(não descer pelo elevador, descer as escadas)

até a garagem da cave, ver o fecho eléctrico abrir-se com dois estalhos e dois sinais de luzes, ver a porta automática subir devagarinho e, logo na rua, acelerar o mais depressa possível [...] (ANTUNES, 2002, p.43)

A problemática conflituosa posta em questão pelo personagem ressalta a fragilidade da existência e suas turbulências. O narrador da trama é o próprio médico, que fala a si mesmo e se vê enclausurado em uma insídia imposta pela condição existencial: a dúvida, a incerteza. É importante ressaltar que António Lobo Antunes inicia o seu texto evocando o hoje, o agora. A sequência de ações descritas na superfície textual sugere uma espécie de fugacidade do tempo, em que tudo parece acontecer rapidamente. Assim, a escolha precisa ser feita, não há como adiar, pois, o tempo se esvai, foge aos nossos olhos e quando se percebe não há mais tempo.

A narrativa nos apresenta um personagem envolvido em um ambiente exato e transparente, em que não há surpresas, apenas a monotonia das horas passadas, vividas sob a amargura de um vazio e uma solidão. Inserido em um universo em que o inesperado não encontra espaço e há apenas o rastro de uma morte simbólica, o médico reverbera: "Hoje estava capaz de me ir embora: as paredes da casa apertam-se, tudo me parece tão pequeno, tão inútil, tão estranho. Fazer romances. Publicá-los. Esperar meses pelo novo romance. Fazê-lo. Publicálo" (ANTUNES, 2002, p. 44). Exaurido em si mesmo, o personagem se encontra cercado de coisas imobilizadas e apenas reconhece conscientemente os seus espaços não preenchidos. A existência do personagem encontra-se encerrada em um ciclo ininterrupto, em que todos os seus atos parecem repetir-se mecanicamente, desprovidos de qualquer júbilo, apenas cumprindo a ordem dos movimentos, das próprias coisas que o cercam.

A exaltação perturbada reprime o subjetivismo do personagem que resvala nas entrelinhas da crônica conduzindo-o a um estágio existencial latente. Nesse momento, compreende-se uma subversão da consciência que extravasa, de maneira a delatar o disfarce da inautenticidade. O filósofo Sartre define essa recusa da liberdade como uma "ameaça imediata e permanente de todo projeto do ser humano, ao fato de a consciência esconder em seu ser um permanente risco de má-fé" (SARTRE, 2008, p. 530). A maneira como o personagem enxerga a sua condição registra o incessante desejo de fuga, de libertar-se da angústia que o aprisiona e entorpece-o, a ponto de almejar a própria morte.

[...] sem uma ideia na cabeça, sem destino, sem mais nada para além desta pressa de me ir embora, colocar entre mim e mim o maior espaço possível, esquecer-me do meu nome, dos nomes dos meus amigos, da minha família, do livro que não acabo de escrever e me angustia. (ANTUNES, 2002, p. 43) 
Tecendo apontamentos filosóficos sobre António Lobo Antunes: uma leitura existencialista da crônica Em caso de acidente

E nesta cena inusitada visualiza-se uma angustiante limitação inerente a qualquer indivíduo e transposta para a superfície linguística textual de maneira laboriosa e inteligível. Percebe-se no texto de António Lobo Antunes um tempo silencioso e um inquietante, acolhidos paralelamente na trama, marcados por uma negação constante a um porvir. Com absurda frieza, o personagem da crônica tenta apagar sua própria história movido por uma aparente resolução, em um processo humano que se determina infindável.

Hoje estava capaz de me ir embora. Metia todo o dinheiro da gaveta no bolso, deixava aqui a carteira, os documentos, os sinais de quem eu sou. Se me perguntarem o que faço responder que não tenho profissão. Sou apenas um homem num restaurante à beira de uma portagem, a mastigar calado. Pode ser que volte um dia, pode ser que não volte. (ANTUNES, 2002, p. 44)

Contudo, não há como livrar-se de um passado, extinguir os fatos, pois o tempo se mostra indivisível ontologicamente. As constantes escolhas realizadas se cristalizam e assumem um caráter estático. Como bem apontou SARTRE (2008, p. 550) "temos plenamente consciência da escolha que somos”. Relativamente a isso, basta lembrar-se da asserção sartriana de que a "liberdade, sendo escolha, é mudança" (SARTRE, 1970, p. 65). O inevitável declive do tempo arquiteta uma luz circunspecta ao homem, tendo em vista que um ser autêntico é responsável por suas escolhas. Desde a concepção socrática, a experiência vivenciada propicia um diálogo consigo e com os outros ao seu redor, originando no homem um pleno cuidado de si.

Considerando a crônica como uma narrativa que nos permite captar o instante, a temporalidade recai sobre o personagem de maneira arrebatadora, é como se o mesmo fosse impelido aos abismos da própria existência.

Podia lê-los enquanto mastigava. Elises Diego, que era poeta, não dá para restaurantes, exige uma intimidade de quando se está sem ninguém na sala. Compôs um poema muito curto sobre a avó dele, em que a avó pede que tapem os espelhos. Ir-me embora é como tapar os espelhos todos sobre mim. Hoje estava capaz de me ir embora. Sem espalhafato, sem conversas, sem explicações, sem essa espiadela de passagem que damos sempre a nós mesmos verificando se o cabelo está certo. (ANTUNES, 2002, p.45)

O olhar-se no espelho é para o personagem uma morte anunciada e sentida como absoluta falta de escolha. Metaforicamente, a imagem do médico no espelho desvenda uma visão de si mesmo e de sua existência, enquanto ser que está intensamente posto em questão e enlaçado nas brechas da inautenticidade, vistos sob um olhar existencialista. Analisando o plano alegórico $^{7}$ visualizam-se duas imagens: a real e a refletida, ou seja, o tempo silencioso e o inquietante respectivamente.

\footnotetext{
7 “Etimologicamente, a alegoria consiste num discurso que faz entender outro, numa linguagem que oculta outra. Pondo de parte as divergências doutrinárias acerca do conceito preciso que o vocábulo encerra, podemos
} 
O tempo inquietante caracteriza-se no texto como os instantes vividos do personagem, que insistem em penetrar no presente, no seu tempo silencioso, incitando reflexões. Impressiona a maneira como as duas dimensões temporais expressas por meio das palavras inquietante e silencioso se contrapõem diante da metáfora surreal da imagem do espelho. Dessa forma, podemos perceber que "o tempo interior que é medido através da sucessão de estados da consciência tem um valor diferente enquanto é vivido e enquanto é rememorado". (MENDILOW, 1972, p. 133)

Construída em camadas temporais diversas que se sobrepõem na tessitura narrativa, a crônica apresenta um personagem angustiado diante do exame de sua existência. Contudo, o mesmo encontra uma decisão confortável para si: tapar os espelhos todos, isentar-se da culpa, da responsabilidade, prefere "ir embora" sem dar explicações, sem conversas. Nesse sentido, Martin Heidegger considera que "o tempo serve como critério para distinguir as regiões e modos de ser" (HEIDEGGER, 2002, p. 55), pois o indivíduo carrega intrínseco em si sensações diversas que se desdobram no presente. Paralelamente a isso, encontra-se inserida na crônica de António Lobo Antunes uma dimensão essencialmente humana: a oscilação dos desejos do ser em virtude do caráter provisório do tempo. A narrativa desenrola-se dentro de um fluxo de consciência caracterizado no plano da diegese por intermédio de um flashback, que faz com que o personagem revisite seu passado, através de suas lembranças.

Quando eu era um médico muito novo, tratei uma senhora de idade que estava a morrer. A meio da tarde perguntou-me:

- Não me acha um bocadinho cansada?

e na manhã seguinte vieram os homens da agência e colocaram-na no caixão. A filha contou-me que depois da pergunta

-Não me acha um bocadinho cansada?

a senhora de idade pediu um cálice de vinho do Porto às escondidas de mim. Metade derramouse no pescoço mas a metade que engoliu animou-a. Era viúva há que tempos e não esperava grande coisa de ninguém. (ANTUNES, 2002, p.45)

O recuo do tempo provoca uma espécie de desencanto no personagem, uma vez que a temporalidade é intuída como uma extensão da grandeza do mundo, em que este se vê enovelado. O médico parece sentir-se desamparado em meio à rememoração de uma desordem que o atemoriza e angustia: o encontro dele mesmo com uma senhora de idade que estava a morrer. Metaforicamente, nesse ato único de um teatro que contempla o drama da existência

considerar alegoria toda concretização, por meio de imagens, figuras e pessoas, de ideias, qualidades ou entidades abstratas. $\mathrm{O}$ aspecto material funcionaria como disfarce, dissimulação ou revestimento, do aspecto moral, ideal ou ficcional. Visto que a narração constitui o expediente mais adequado à concretização do mundo abstrato, tem-se como certo que a alegoria implica sistematicamente um enredo, teatral ou novelesco. E daí a impressão de equivaler a uma sequência logicamente ordenada de metáforas: o acordo entre o plano concreto e o plano abstrato processa-se minúcia a minúcia, elemento a elemento, e não em sua totalidade”. (MOISÉS, 1982, p. 15) 
Tecendo apontamentos filosóficos sobre António Lobo Antunes: uma leitura existencialista da crônica Em caso de acidente

interpenetram faces diversas - jovialidade e sabedoria - que se relacionam a partir da indagação ontológica: "Não me acha um bocadinho cansada?" (ANTUNES, 2002, p. 45), num dado momento da existência de ambos os personagens.

O filósofo Sartre enfatiza que "o tempo me separa de mim mesmo, daquilo que fui, do que quero ser, do que quero fazer, das coisas e do outro" (SARTRE, 2008, p. 546). Ao mesmo tempo em que causa um conflito angustiante, o efêmero alivia o ser, pois tudo passa rapidamente. Contudo, pode deixar cicatrizes que nem mesmo o temporário consegue apagar e insistem em impregnar o presente. A representação de dois mundos a partir de nuances visuais expõe o médico diante de si mesmo por si mesmo, em que o tempo o arremessa, radicalmente, ao seu introspectivo. Com relação a isso, Ricoeur afirma que o "narrador jamais confronta duas entidades, duas categorias - mesmo que sejam existenciais no sentido de Heidegger -, mas duas experiências-limite, entre as quais reparte toda a gama das experiências singulares que escolheu para encenar" (RICOEUR, 1997, p. 66).

Assim, no texto literário há o confronto entre o tempo e o personagem, que se encontra imerso em um paradoxo de representações de vivências, singulares e incomparáveis, que não se repetirão jamais. Desse modo, podemos apreender que mesmo que sejam recriadas as mesmas circunstâncias em que foram vividas, não há como o homem voltar no tempo, não há como reconstruir o mesmo significado de outrora. Na busca de caminhos elucidativos e significações que alcancem a escrita enigmática de António Lobo Antunes é que a presença de Sartre se torna imprescindível, pois permite questionar o real sentido da existência humana, a partir do fazer literário do autor português, propiciando a abertura de discussões acerca da experiência, de fragmentos vivos e concretos de material humano.

Contemplando em sua narrativa o absurdo da existência e revelando as contrariedades que a inquietam, António Lobo Antunes deixa transparecer substâncias existenciais que enfatizam o processo de escolha, posto que uma decisão num dado instante pode modificar a existência. No entanto, às vezes, isso só é abarcado nos momentos finais que revelam a completude existencial. Na crônica Em caso de acidente (2002) o personagem se percebe esvaziado subjetivamente, apenas sob a penumbra de um passado rememorado, não vivido, vislumbrado através da intensa cumplicidade de si a si.

A vivência alterada se dá no contraponto de dois mundos, sem pontos de contato, chocando-se e possibilitando a abertura de novos campos de tensão. Assim, apreende-se no personagem da referida crônica a extrema necessidade de um encontro consigo mesmo, marcado na instância narrativa pelo próprio tempo, em um convite forçado e sufocante. A insensatez que norteia a existência do personagem se perde na multiplicidade de representações 
configuradas pela temporalidade. Como toda experiência humana se transforma em passado, o presente se manifesta como "um agora" que está impregnado de instantes pretéritos e do porvir, marcados fortemente por escolhas eleitas no cotidiano, corroborando, dessa forma, que "[...] o tempo nunca é todo presente" (AGOSTINHO, 1981, p. 301).

A infinita gama de ambições e planos sonhados pelo indivíduo o projeta como um serpara-si, ou seja, que tem consciência da própria condição. Na citada crônica, o personagem é lançado em uma apreciação profunda do seu 'eu presente', num embate incomensurável entre o em-si e o para-si, pondo em questão duas personae que estão separadas ontologicamente pelo tempo. Assim, o ser-para-outrem se manifesta na percepção do outro em minha existência, a partir das experiências adquiridas na minha exterioridade e que iluminam o ser na compleição de um para-si pleno. O personagem se descobre posteriormente como um ser livre e capaz de realizar escolhas: "Há momentos na vida que necessitamos tanto de um sorriso. À falta de melhor toco-me com o dedo no caixilho" (ANTUNES, 2002, p. 45). A consciência da passagem do tempo o leva a refletir sobre a brevidade da vida. A existência plena é repensada pelo personagem de maneira nítida e sem subterfúgios, trazendo à tona a compreensão de que "a vivência subjetiva do tempo nada tem que ver com o tempo dos relógios" (ROSENFELD, 1996, p. 82).

O que dirá o editor francês, o editor alemão, o editor sueco? Cartas desesperadas do agente que nunca receberei, telegramas intactos na caixa do correio reclamando uma obra pela qual me pagaram e que deixei, incompleta, por alturas do penúltimo capítulo, por corrigir, por alterar. (ANTUNES, 2002, p.45)

O desconforto perante o mundo faz com que o personagem reelabore outro modus vivendi, pois assim como os editores reclamam por textos inacabados, a consciência exige, em seu tempo oportuno, a responsabilidade por cada escolha, ou seja, "cada coisa tem seu próprio tempo" (HEIDEGGER, 1989, p. 206). A existência do homem está fadada às constantes escolhas que o mesmo elege a cada instante que passa e carrega consigo o peso da responsabilidade advinda dessas mesmas escolhas.

\section{Referências}

ANTUNES, António Lobo. Segundo Livro de Crônicas. Lisboa: Publicações Dom Quixote, 2002.

AGOSTINHO, Santo. Livro Onze: O homem e o tempo. In. Confissões. $10^{\mathrm{a}}$ ed. Livraria Apostolado da Imprensa: Porto, 1981. 
Tecendo apontamentos filosóficos sobre António Lobo Antunes: uma leitura existencialista da crônica Em caso de acidente

BÍBLIA, A. T. Eclesiastes. Português. Bíblia Sagrada. 14ª ed. Versão dos Monges Beneditinos de Maredsous. São Paulo: Ave Maria, 2013, p. 818.

FLORY, Suely Fadul Villibor. O Leitor e o labirinto. São Paulo: Arte e Ciência, 1997.

GOMES, Álvaro Cardoso de. A voz itinerante. Ensaio sobre o romance português contemporâneo. São Paulo: Editora da Universidade de São Paulo, 1993.

HEIDEGGER, Martin. Ser e tempo. Parte I. 12a ed. Tradução de Márcia Sá Cavalcante Schuback. Petrópolis: Vozes, 2002.

. Tempo e ser. In. Conferências e escritos filosóficos. Tradução e notas de Ernildo Stein. São Paulo: Nova Cultural, 1989.

HUISMAN, Denis. História do existencialismo. São Paulo: EDUSC, 2001.

MOISÉS, Massaud. A literatura portuguesa. 36a ed. São Paulo: Cultrix, 2008.

Dicionário de termos literários. $3^{\mathrm{a}}$ ed. São Paulo: Cultrix, 1982.

MENDILOW, Adam Abraham. O tempo e o romance. Tradução de Flávio Wolf. Porto Alegre: Globo, 1972.

RICOEUR, Paul. Tempo e narrativa. Tomo III. Tradução de Roberto Leal Ferreira. São Paulo/Campinas: Papirus, 1997.

ROSENFELD, Anatol. Reflexões sobre o romance moderno. In. Texto e contexto. São Paulo: Perspectiva, 1996.

SARTRE, Jean Paul. O Ser e o nada. Ensaio de Ontologia Fenomenológica. Tradução de Paulo Perdigão. Petrópolis: Vozes, 2008.

O Existencialismo é um humanismo. Tradução e notas de Vergílio

Ferreira. Lisboa: Editorial Presença, 1970.

SOARES, Angélica. Gêneros literários. 4ª ed. São Paulo: Ática, 1999. 